\title{
Effect of short-time external short circuiting on the capacity fading mechanism during long-term cycling of \\ $\mathrm{LiCoO}_{2} /$ mesocarbon microbeads battery
}

Lingling Zhang ${ }^{\text {a }}$, Xinqun Cheng ${ }^{\mathrm{a}, *}$, Yulin Ma ${ }^{\text {a }}$, Ting Guan ${ }^{\mathrm{a}}$, Shun Sun ${ }^{\text {a }}$, Yingzhi

Cui ${ }^{\text {a }}$, Chunyu Du ${ }^{\text {a }}$, Pengjian Zuo a , Yunzhi Gao ${ }^{\text {a }}$, Geping Yin ${ }^{\text {a, } *}$

${ }^{\text {a }}$ Institute of Advanced Chemical Power Sources, School of Chemical Engineering and Technology, Harbin Institute of Technology, Harbin 150001, China

*Corresponding author: Xinqun Cheng, Geping Yin (G. P. Yin)

E-mail: chengxq@hit.edu.cn (X. Q. Cheng), yingeping@hit.edu.cn (G. P. Yin)

Telephone number: $86-451-86413721$

Fax number: 86-451-86403807

Postal address: Institute of Advanced Chemical Power Sources, School of Chemical Engineering and Technology, Harbin Institute of Technology, Harbin 150001, China

Abatract: Commercial $\mathrm{LiCoO}_{2} /$ mesocarbon microbeads (MCMB) batteries (CP475148AR) are short circuited by different contact resistances $(0.6 \mathrm{~m} \Omega$ and 5.0 $\mathrm{m} \Omega$ ) for short times. The short circuited battery is cycled for 1000 times, and the effect of the short-time external short circuiting on the capacity fading mechanism 
during long-term cycling of $\mathrm{LiCoO}_{2} / \mathrm{MCMB}$ battery is studied by analyzing the morphology, structure, and electrochemical performance. The results of SEM indicates that the morphology of $\mathrm{LiCoO}_{2}$ material is almost unchanged, except that the particle surface becomes smooth, and the solid electrolyte interphase (SEI) film on the surface of MCMB electrode becomes nonuniform due to the high temperature caused by short circuiting. The lithium ions are more difficult to de-intercalate from the anode and the lattice structure of $\mathrm{LiCoO}_{2}$ degrades according to the results of X-ray diffraction (XRD). The high discharge current caused by short circuiting can damage electrodes, leaving vacancies in structure. The damage of electrode structure can lead to a decrease of diffusion coefficient of lithium $\left(D_{\mathrm{Li}}{ }^{+}\right)$, so polarization increases and mainly caused by the $\mathrm{LiCoO}_{2}$ electrode. The capacity deterioration of short circuited battery during long-term cycling is mainly caused by the increase of polarization and capacity loss of electrodes.

Keywords: $\mathrm{LiCoO}_{2} / \mathrm{MCMB}$ battery, External short circuiting, Long-term cycling, Capacity fading mechanism, Polarization, The diffusion coefficient of lithium

\section{Introduction}

Lithium-ion battery has been extensively used in mobile communication and portable instruments [1-3]. However, the safety of lithium-ion batteries is still a major weakness [4-6], though many methods have been engineered to minimize the causes of safety failures. The process of engineering included studies of safety problems and failure mechanisms associated with the external short circuiting, over-discharging, and over-charging $[7,8]$. 
The capacity-fading mechanism during long-term cycling of over-discharged $\mathrm{LiCoO}_{2} / \mathrm{MCMB}$ batteries has been studied in our previous work [9]. It was found that serious over-discharging can reduce the battery capacity obviously, and that the capacity fading is mainly related to the deposition of copper on anode.

Battery failure due to short circuiting is also a particular concern for practical application because short circuiting in battery packs can result in smoke or combustion [10]. The failure of batteries after being short circuited is mainly related to the melting of separators $[11,12]$. Ceramic-coated separator is used in the lithium-ion batteries because it can reduce the degree of heat shrinkage of separator [13-15]. Sometimes, external short circuiting may happen due to operating mistakes (electrode connection, et al.). However, the separator isn't melted, owing to the high contact resistance or the short contact time. In other words, the battery may not be failed even though the battery has undergone short circuiting. Therefore, it is necessary to analyze whether these batteries can work normally or not and analyze the effects of external short circuiting on the performance during long-term cycling of these batteries. Additionally, a comprehensive analysis of short circuited battery aging is beneficial for the diagnosis of battery performance and the estimation of state-of-safety (SOS), which can help to refine the safety standard and facilitate more effectively resource utilization. To our knowledge, there are no reports related to the effect of short-time external short circuiting on the capacity fading mechanism during long-term cycling of $\mathrm{LiCoO}_{2} /$ mesocarbon microbeads (MCMB) batteries.

In our study, the effect of short-time external short circuiting on the capacity 
fading mechanism during long-term cycling of $\mathrm{LiCoO}_{2} / \mathrm{MCMB}$ battery was investigated. A shallow discharge cycle system is often used by power supplies for smart-grid electricity systems and satellites. The battery was externally short circuited by a contact resistance for short contact time. The short circuiting mode was $0.6 \mathrm{~m} \Omega$ $1 \mathrm{~s}, 5.0 \mathrm{~m} \Omega 30 \mathrm{~s}, 0.6 \mathrm{~m} \Omega 30 \mathrm{~s}$ and $5 \mathrm{~m} \Omega 180 \mathrm{~s}$. Electrochemical tests on full batteries and half-cells $\left(\mathrm{Li} / \mathrm{LiCoO}_{2}\right.$ and $\left.\mathrm{Li} / \mathrm{MCMB}\right)$ were conducted to analyze the change of the performance of full batteries and intrinsic performance of each electrode, respectively. The structure and surface morphology of both $\mathrm{LiCoO}_{2}$ and $\mathrm{MCMB}$ electrodes disassembled from the short-time short circuited batteries (BS) and from batteries short-time short circuited and then cycled for 1000 times (BSC) were investigated by X-ray diffraction (XRD) and scanning electron microscopy (SEM), respectively. And potentiostatic intermittent titration technique (PITT) was applied to calculate the electrochemical kinetic parameters such as chemical diffusion coefficient of $\mathrm{Li}^{+}\left(D_{\mathrm{Li}}{ }^{+}\right)$in $\mathrm{LiCoO}_{2}$ electrode.

\section{Experimental}

The type of commercial prismatic $\mathrm{LiCoO}_{2} / \mathrm{MCMB}$ battery used in this experiment was CP475148AR, which means a prismatic battery with the dimension of $4.7 \mathrm{~mm}$ thickness, $51 \mathrm{~mm}$ width, and $48 \mathrm{~mm}$ in height. The rated capacity of designed battery at $1 \mathrm{C}$ was $1150 \mathrm{mAh}$ with a capacity ratio of anode to cathode of about 1.05 , and a battery resistance of about $35 \mathrm{~m} \Omega$. The cathode was composed of $97.2 \mathrm{wt} \%$ $\mathrm{LiCoO}_{2}, 1.3 \mathrm{wt} \%$ Vapor-grown carbon fiber (VGCF) and $1.5 \mathrm{wt} \%$ polyvinylidene fluoride (PVDF) binder. The anode was composed of $92 \mathrm{wt} \% \mathrm{MCMB}, 2 \mathrm{wt} \%$ super-P, 
$6 \mathrm{wt} \% \mathrm{PVDF}$ binder. The electrolyte was $1 \mathrm{~mol} / \mathrm{L} \mathrm{LiPF}_{6}$ in ethylene carbonate/diethyl carbonate/ethyl methyl carbonate (EC/DEC/EMC, 1:1:1 by volume).

The battery was charged to $4.2 \mathrm{~V}$ at $0.6 \mathrm{C}$ ( $\mathrm{CC}$ mode), followed by a constant voltage $(4.2 \mathrm{~V})$ until the current decreased to $0.02 \mathrm{C}(\mathrm{CV}$ mode), and then the battery was discharged to $3.0 \mathrm{~V}$ at $0.6 \mathrm{C}$ and was considered as activated battery. $0.6 \mathrm{C}$ rate means the current was $690 \mathrm{~mA}$. Before short circuiting, the battery was charged/discharged for two cycles at $0.6 \mathrm{C}$ between $3.0 \mathrm{~V}$ and $4.2 \mathrm{~V}$, and the measured capacity was considered as the initial capacity of the battery. After that, the battery is charged to $4.2 \mathrm{~V}$ at $0.6 \mathrm{C}$ by $\mathrm{CC}-\mathrm{CV}$ mode, and then the full charged battery was externally short circuited by copper wires (resistance: $0.6 \mathrm{~m} \Omega$ and $5.0 \mathrm{~m} \Omega$ ) for short times. Current changes during short circuiting tests were recorded with a current converter device. The external surface temperatures of batteries were measured by K-type thermocouples. The short circuiting mode was $0.6 \mathrm{~m} \Omega 1 \mathrm{~s}, 5.0 \mathrm{~m} \Omega 30 \mathrm{~s}, 0.6$ $\mathrm{m} \Omega 30 \mathrm{~s}$ and $5 \mathrm{~m} \Omega 180 \mathrm{~s}$, respectively.

These short circuited batteries were kept at room temperature to ensure the inside temperature down to room temperature, then discharged at $0.6 \mathrm{C}$ to $3 \mathrm{~V}$, and cycled for two times to determine the reversible capacity at $0.6 \mathrm{C}$ between $3 \mathrm{~V}$ and $4.2 \mathrm{~V}$. After that, the short circuited batteries were cycled for 1000 times with 30\% DOD (depth of discharge) at $0.6 \mathrm{C}$. During each cycle, the battery was charged to $4.2 \mathrm{~V}$ (CC-CV mode) at $0.6 \mathrm{C}$, then the battery was discharged at $0.6 \mathrm{C}$ to release $30 \%$ of the initial capacity. The reversible capacity of each battery was verified every 100 cycles by using two full charge/discharge tests. The battery, which was externally short circuited and then 
cycled for 1000 times at $0.6 \mathrm{C}$ and 30\% DOD was labeled as BSC. Batteries which were externally short circuited by different mode were labeled as BS. The activated battery was also cycled for 1000 times, as a comparison with the BSC, and was labeled as blank battery. The external short circuiting mode of batteries and the labeled abbreviations are listed in table 1.

The electrochemical impedance spectroscopy (EIS) measurement was conducted during the frequency range of $20 \mathrm{kHz}$ to $5 \mathrm{mHz}$ with an amplitude of $5 \mathrm{mV}$. After being externally short circuited for short time, the battery was cycled for two times, and then the EIS was measured. The battery was dismantled at discharged state for safe operation; accordingly, the EIS measurement was performed at discharged state in our work. In addition, EISs of the activated battery and blank battery were also measured as a comparison.

The BS and BSC were disassembled in discharged state in a glove box filled with pure argon $\left(<1 \mathrm{ppm} \mathrm{H}_{2} \mathrm{O},<10 \mathrm{ppm} \mathrm{O}_{2}\right)$. The $\mathrm{MCMB}$ and $\mathrm{LiCoO}_{2}$ electrodes were immersed in DMC to remove the electrolyte and then dried in a vacuum. Active materials on one side of the electrodes were removed by n-methyl-pyrrolidinone (NMP). Then $\mathrm{LiCoO}_{2}$ and MCMB electrodes were punched out and coin cells (CR2025) were assembled in the glove box with lithium foil used as the counter electrode. The $\mathrm{Li} / \mathrm{LiCoO}_{2}$ (or $\mathrm{Li} / \mathrm{MCMB}$ ) coin cells were cycled in order to check the reversible capacity and residual capacity of $\mathrm{LiCoO}_{2}$ (or MCMB) electrodes. The $\mathrm{Li} / \mathrm{LiCoO}_{2}$ cells were charged and discharged using $\mathrm{CC}-\mathrm{CV}$ mode at $0.1 \mathrm{C}$ between 3.0 and $4.3 \mathrm{~V}$ and the $\mathrm{Li} / \mathrm{MCMB}$ cells were charged and discharged at $0.05 \mathrm{C}$ between 
$0.01 \mathrm{~V}$ and $1.5 \mathrm{~V}$.

The structural characterization of the active materials was tested by X-ray diffraction (XRD) using a Rigaku D/max- $\gamma \mathrm{B}$ diffractometer from $10^{\circ}$ to $90^{\circ}(\mathrm{Cu} \mathrm{K} \alpha$ radiation). The surface morphology of the electrodes material was observed by scanning electron microscopy (SEM) using a Helios Nanolab600i microscope equipped with energy dispersive spectrometry (EDS).

The chemical diffusion coefficient of lithium $\left(D_{\mathrm{Li}}{ }^{+}\right)$was measured by potentiostatic intermittent titration technique (PITT). A potential step of $25 \mathrm{mV}$ was applied and the current was recorded as a function of time. The potential was stepped to the next level when the current decreased to below $0.1 \mu \mathrm{A} \mathrm{cm}{ }^{-2}$. The procedure was repeated between 3.95 and $4.3 \mathrm{~V}$. The rate-capability of the $\mathrm{LiCoO}_{2}$ electrode was performed by CC-CV mode at different C-rates, varying between $0.1 \mathrm{C}$ and $1 \mathrm{C}$. All the tests were conducted in an air-conditioned room, and the temperature was controlled at $25 \pm 2{ }^{\circ} \mathrm{C}$.

\section{Results and discussion}

The battery was externally short circuited by the mode of $0.6 \mathrm{~m} \Omega 1 \mathrm{~s}, 5.0 \mathrm{~m} \Omega 30 \mathrm{~s}$, $0.6 \mathrm{~m} \Omega 30 \mathrm{~s}$, and $5 \mathrm{~m} \Omega 180 \mathrm{~s}$. The changes of current, voltage, and exterior temperature of the batteries are shown in Fig. 1. The battery voltage dropped from 4.2 to about $0 \mathrm{~V}$, instantaneously after the battery was short circuited, while the peak current instantly reached to about $40 \mathrm{~A}$, and the exterior temperature of battery short circuited by different modes $(0.6 \mathrm{~m} \Omega 1 \mathrm{~s}, 5.0 \mathrm{~m} \Omega 30 \mathrm{~s}, 0.6 \mathrm{~m} \Omega 30 \mathrm{~s}$ and $5.0 \mathrm{~m} \Omega 180 \mathrm{~s})$ rose to a maximum value of $33^{\circ} \mathrm{C}, 63^{\circ} \mathrm{C}, 76^{\circ} \mathrm{C}$ and $115^{\circ} \mathrm{C}$, respectively. 
Fig. 1.

\subsection{Electrochemical tests}

When the battery is externally short circuited by the mode of $0.6 \mathrm{~m} \Omega 1 \mathrm{~s}, 5.0 \mathrm{~m} \Omega$ $30 \mathrm{~s}, 0.6 \mathrm{~m} \Omega 30 \mathrm{~s}$ and $5 \mathrm{~m} \Omega 180 \mathrm{~s}$, the capacity loss is $0.53 \%, 8.92 \%, 34.08 \%$ and $77.45 \%$, respectively. Therefore, a slight short circuiting $(0.6 \mathrm{~m} \Omega 1 \mathrm{~s})$ has little effect on the performance of battery while serious short circuiting can reduce the battery capacity obviously. After external short circuiting, these batteries, except the battery short circuited by $5 \mathrm{~m} \Omega 180 \mathrm{~s}$, were cycled 1000 times at $0.6 \mathrm{C}$ with $30 \%$ DOD. The capacity retention and the voltage at the end of discharge of these batteries during 1000 cycles are presented in Fig. 2. Results show that slight short circuiting has little effect on further use while serious short circuiting can accelerate capacity fading during long-term cycling. The capacity retention of blank battery is $93.06 \%$, while the capacity retention of BSC by different mode $(0.6 \mathrm{~m} \Omega 1 \mathrm{~s}, 5.0 \mathrm{~m} \Omega 30 \mathrm{~s}$, and $0.6 \mathrm{~m} \Omega$ $30 \mathrm{~s}$, respectively) is $90.57 \%, 75.90 \%$, and $36.54 \%$, respectively, which are reduced by $2.48 \%, 17.16 \%$, and $56.52 \%$ by comparing with that of blank battery, respectively. In addition, by comparing with that of BS, the capacity retentions of BSC are reduced by $8.90 \%$ for $0.6 \mathrm{~m} \Omega 1 \mathrm{~s}, 15.18 \%$ for $5.0 \mathrm{~m} \Omega 30 \mathrm{~s}$, and $29.38 \%$ for $0.6 \mathrm{~m} \Omega 30 \mathrm{~s}$, respectively. These results indicate that cycling can accelerate capacity decay of short circuited battery, and the capacity fading exacerbates with the increasing of short circuiting degree. It can be seen from Fig. $2 b$ that the first discharge cutoff voltages of 
BS are deceases by $0.02 \mathrm{~V}$ for $0.6 \mathrm{~m} \Omega 1 \mathrm{~s}, 0.10 \mathrm{~V}$ for $5.0 \mathrm{~m} \Omega 30 \mathrm{~s}$, and $0.25 \mathrm{~V}$ for 0.6 $\mathrm{m} \Omega 30 \mathrm{~s}$, respectively, indicating that serious short circuiting can increase the polarization of battery. Compared with the voltage at the end of discharge of blank battery $(0.02 \mathrm{~V})$, the voltage of BSC is reduced by $0.06 \mathrm{~V}, 0.20 \mathrm{~V}$, and $0.46 \mathrm{~V}$, respectively, indicating that the polarization of BS increases after cycling.

\section{Fig. 2.}

For illustration purposes, $\mathrm{Q}_{1}$ is defined as the capacity loss caused by the short circuiting test, $\mathrm{Q}_{1000}$ as the total capacity loss caused by both 1000 cycles and short circuiting test, and $\mathrm{R}$ as the ratio of $\mathrm{Q}_{1}$ and $\mathrm{Q}_{1000}$. Table 2 shows $\mathrm{Q}_{1}, \mathrm{Q}_{1000}$ and $\mathrm{R}$ of the battery. $\mathrm{R}$ increases with the increase of short circuiting degree, indicating that short circuiting is a significant reason for capacity loss. BS and BSC are further analyzed in order to analyze the effect of short-time external short circuiting on capacity fading during the long-term cycling of the battery.

\section{Table 2}

Fig. 3 shows normalized charge/discharge profiles of BS and BSC. The profile of battery externally short circuited by $0.6 \mathrm{~m} \Omega$ for $1 \mathrm{~s}$ has no obvious change. However, for the battery externally short circuited by $5.0 \mathrm{~m} \Omega 30 \mathrm{~s}, 0.6 \mathrm{~m} \Omega 30 \mathrm{~s}$, and $5.0 \mathrm{~m} \Omega 180 \mathrm{~s}$, the lithium-intercalation platform rises and the lithium-deintercalation platform drops, which indicates the increasing of polarization [16]. And the 
polarization is gradually increscent with the increase of short circuiting degree. Additionally, the polarization of BSC also increases, indicating that polarization is further intensified after cycling.

Fig. 3.

The impedances of BS and BSC were tested and the fitted results are shown in Fig. 4. It can be seen from Fig. 4a that the impedance has almost no change for the battery externally short circuited by $0.6 \mathrm{~m} \Omega$ for $1 \mathrm{~s}$ while the impedance dramatically increased when the battery is seriously short circuited by $5.0 \mathrm{~m} \Omega 30 \mathrm{~s}, 0.6 \mathrm{~m} \Omega 30 \mathrm{~s}$, and $5 \mathrm{~m} \Omega$ 180s, indicating that serious short circuiting can increase the overall impedance of battery. For the BSC by $0.6 \mathrm{~m} \Omega 1 \mathrm{~s}$, the impedance is quite close to the blank battery. However, the impedance of BSC by $5.0 \mathrm{~m} \Omega 30 \mathrm{~s}$ and $0.6 \mathrm{~m} \Omega 30 \mathrm{~s}$ increases obviously, indicating that impedance of short circuited battery increases after cycling. $R_{b}$ and $R_{1}$ slightly increase while $R_{2}$ increases rapidly with the increase of short circuiting degree from Fig. $4 b$. The meanings of $R_{b}, R_{1}$, and $R_{2}$ have been mentioned in the relevant literatures [17-19]. $R_{b}$ is related to the increase of total internal ohmic resistance from the electrolyte, the electrodes, and the internal connections. $\mathrm{R}_{1}$ represents the resistance featuring interfacial contributions like passivating films. $\mathrm{R}_{2}$ features charge-transfer resistance at the electrode/electrolyte interface. According to the above analysis, the short circuiting can lead to low voltage, high temperature, and high current. High discharge current may result in serious side reactions on the electrode/electrolyte interface, the instability of SEI film, and the 
damage of electrode structure [20]. The high temperature can accelerate the decomposition of electrolyte and the side reactions between electrode/electrolyte interface [21, 22]. Therefore, serious short circuiting can lead to the growth of SEI film on the surface of MCMB electrode, the decrease of reactivity of lithium intercalation and de-intercalation, and the electrochemical reaction becomes more difficult. The relative evolutions of $\mathrm{R}_{\mathrm{b}}, \mathrm{R}_{1}$, and $\mathrm{R}_{2}$ of $\mathrm{BSC}$ are also derived from the Nyquist plots, and the variation trend is similar with $\mathrm{BS}$. $\mathrm{R}_{2}$ increases the most among all different contributions after external short circuiting test, suggesting that the reactivity of lithium intercalation and de-intercalation declines for BS by $0.6 \mathrm{~m} \Omega 30 \mathrm{~s}$ after 1000 cycles. Thus, the electrochemical reaction is becoming more difficult.

Fig. 4.

\subsection{Morphology of the electrodes}

The BS and BSC were dismantled in the discharged state. Fig. S1 shows the digital photographs of $\mathrm{LiCoO}_{2}$ and $\mathrm{MCMB}$ electrodes disassembled from BS. The influence of the short circuiting conditions manifests itself by a change of the electrode color. There is no obvious color change of short circuited $\mathrm{LiCoO}_{2}$ electrode (Fig. S1(a-e)). For the MCMB electrode, no obvious color change is observed for the MCMB dismantled from BS by $0.6 \mathrm{~m} \Omega 30$ s or lower degree (Fig. S1(f-i)), but the electrode becomes much harder. The originally dark areas become obviously brown when the battery is short circuited by $5 \mathrm{~m} \Omega 180$ s (Fig. S1j). The color of MCMB 
electrode depends on its lithium content [23], which suggests that the MCMB electrode short circuited by $5 \mathrm{~m} \Omega 180$ s are not fully delithiated, even though the battery is discharged to $3.0 \mathrm{~V}$.

The morphology of $\mathrm{LiCoO}_{2}$ short circuited by $0.6 \mathrm{~m} \Omega$ for $30 \mathrm{~s}$ or slighter has no obvious morphology change (Fig. S2(a-d)). When the battery is externally short circuited by $5 \mathrm{~m} \Omega 180 \mathrm{~s}$, a layer of material covers on the surface of the $\mathrm{LiCoO}_{2}$ particles, resulting in particle much smoother (Fig. S2e). The morphology of $\mathrm{LiCoO}_{2}$ particles from BSC has also no obvious change, though the battery was cycled for 1000 times (Fig. S2(f-i)).

The morphology of MCMB electrode dismantled from BS by $0.6 \mathrm{~m} \Omega 1 \mathrm{~s}$ has no obvious change (Fig. S3b). Some particle facets develop roughing when short circuiting intensifies, especially for the MCMB electrode under the most severe conditions (5 m $\Omega$ 180s) from Fig. S3(b-e). The apparent roughness of MCMB surface is likely related to the SEI film that becomes fluffy as it grows. According to the results of the EDS analysis (Table 3), the oxygen content increases with the increase of short circuiting degree, which might be related with the presence of lithium compounds such as $\mathrm{Li}_{2} \mathrm{CO}_{3}$ or lithium alkylcarbonates on the particle surface [24]. The EDS analyses show that fluorine is rich in the MCMB electrode from the battery short circuited by $5 \mathrm{~m} \Omega 180 \mathrm{~s}$, which might be attributed to the content increase of LiF [25]. The lithium compounds derived from the interfacial reactions are deposited on the surface of MCMB electrode, owing to the high temperature caused by short circuiting, which can result in the deterioration of MCMB electrode. Additionally, 
viewing shows that the particle surface of MCMB also becomes much rougher after 1000 cycles (Fig. S3(f-i)).

Table 3

\subsection{XRD measurements}

Fig. 5 shows the XRD patterns of the $\mathrm{LiCoO}_{2}$ electrodes dismantled from $\mathrm{BS}$ and BSC in the discharged state. The XRD results in Fig. 5a show that there is no significant difference, and only the peaks of $\mathrm{LiCoO}_{2}$ can be detected from BS by 0.6 $\mathrm{m} \Omega 30 \mathrm{~s}$ or slighter. For the battery short circuited by $5 \mathrm{~m} \Omega 180 \mathrm{~s}$, the peaks of $\mathrm{Li}_{1-\mathrm{x}} \mathrm{CoO}_{2}$ can be detected, indicating that part of the cathode material isn't fully interlithiated, even though the battery is discharged to $3.0 \mathrm{~V}$. Additionally, there is no significant difference between $\mathrm{BS}$ and $\mathrm{BSC}$, and only the peaks of $\mathrm{LiCoO}_{2}$ are detected. The partial enlargement of peak (003) and (104) of $\mathrm{LiCoO}_{2}$ electrodes is shown in Fig. 5b. The peak (003) and (104) of $\mathrm{LiCoO}_{2}$ electrodes dismantled from BS shifts towards a low angle slightly with the rising of short circuiting degree, indicating residual the increase of lithium vacancies $[26,27]$. The lithium ions lost from $\mathrm{LiCoO}_{2}$ can be caused by lithium compound deposition on the surface of the MCMB electrode, which was confirmed by the EDS. However, the peak (003) and (104) of BSC also shifts towards a low angle and become broader. The peak (003) of BSC by $0.6 \mathrm{~m} \Omega$ 30s splits into two peaks, which may relate to the formation of a disordered phase involving Li and Co cation mixing $[28,29]$. The ratio of $\mathrm{I}_{003} / \mathrm{I}_{104}$ and the FWHM of 
peak (003) of $\mathrm{LiCoO}_{2}$ from BS and BSC are listed in Table 4. The ratio of $\mathrm{I}_{003} / \mathrm{I}_{104}$ of $\mathrm{LiCoO}_{2}$ from BS reduces with the rising of short circuiting degree, which suggests the increase of the degree of $\mathrm{Li}^{+} / \mathrm{Co}^{3+}$ cation mixing. High current caused by short circuiting can damage the electrode, leaving vacancies in the structure, which can retard the diffusion of lithium ions from the cathode [30].

The $\mathrm{I}_{003} / \mathrm{I}_{104}$ of $\mathrm{LiCoO}_{2}$ dismantled from $\mathrm{BSC}$ reduces much larger with the increase of short circuiting degree. The full-width of at half maximum (FWHM) of peak (003) of $\mathrm{LiCoO}_{2}$ from BS shows an initial increase slowly, which may result from internal strains within the crystallites and/or from a decrease in the coherence length along the c-axis [31]. The FWHM of peak (003) shows an initial slowly increase for BSC by $0.6 \mathrm{~m} \Omega 1 \mathrm{~s}$ and $5 \mathrm{~m} \Omega 30 \mathrm{~s}$ while the FWHM of peak (003) of BSC by $0.6 \mathrm{~m} \Omega 30$ s increases obviously. These results indicate that the charge-discharge cycle intensifies the structure change of $\mathrm{LiCoO}_{2}$ in $\mathrm{BSC}$.

Fig. 5.

Table 4.

The XRD full patterns of the MCMB electrodes from BS are presented in Fig. 6a. The diffraction peaks of MCMB electrodes from battery externally short circuited by $0.6 \mathrm{~m} \Omega 30$ s or slighter have the same peak positions as those of the activated anode, and a diffraction peak at $2 \theta=26.381^{\circ}$ can be detected. Obvious peaks of $\operatorname{LiC}_{12}(2 \theta=$ $25.281^{\circ}$ ) appeared in the XRD pattern of MCMB electrode, which was short circuited 
by $5 \mathrm{~m} \Omega 180 \mathrm{~s}$. The appearance of $\mathrm{LiC}_{12}$ indicates that MCMB electrode is not fully delithiated though the battery is discharged to $3.0 \mathrm{~V}$. And the XRD results are also consistent with the color change of MCMB electrode. These results indicate that, though the short circuited battery is fully discharged, the amount of intercalated lithium is obviously less than that of activated anode. Accordingly, it can be speculated that lithium ions are more difficult to de-intercalate from anode of BS, leading to the increase of polarization.

The XRD full spectra of MCMB electrode dismantled from BSC are depicted in Fig. 6b. Compared to the blank anode, the characteristic peaks of MCMB from BSC have no obvious change, indicating that the structure of short circuited MCMB electrode still remains unchanged after 1000 cycles. Therefore, by the comprehensive analysis on the results of SEM, EDS and XRD, serious short circuiting makes lithium ions more difficult to de-intercalation from anode and the structure of short circuited $\mathrm{LiCoO}_{2}$ slightly changes after 1000 cycles.

Fig. 6.

\subsection{Coin cell tests}

CR2025 coin cell ( $\mathrm{Li} / \mathrm{LiCoO}_{2}$ and $\left.\mathrm{Li} / \mathrm{MCMB}\right)$ was used to test the performance of $\mathrm{LiCoO}_{2}$ and $\mathrm{MCMB}$ electrode dismantled from BS and BSC. The reversible and residual capacity of the $\mathrm{LiCoO}_{2}$ and MCMB electrodes were evaluated at low rate.

The ratios of capacity loss for $\mathrm{LiCoO}_{2}$ and MCMB electrode dismantled from BS 
and BSC are listed in Table 5. The capacities of $\mathrm{LiCoO}_{2}$ and $\mathrm{MCMB}$ electrodes short circuited by $0.6 \mathrm{~m} \Omega$ for $1 \mathrm{~s}$ almost have no fading. When the battery is short circuited by $5.0 \mathrm{~m} \Omega$ for $30 \mathrm{~s}$, the $\mathrm{LiCoO}_{2}$ and MCMB electrode still have high specific capacity at low rate. The capacity loss of $\mathrm{LiCoO}_{2}$ and $\mathrm{MCMB}$ electrode dismantled from the battery short circuited by $0.6 \mathrm{~m} \Omega$ for $30 \mathrm{~s}$ is $6.39 \%$ and $4.52 \%$, respectively. The MCMB electrodes dismantled from battery short circuited by $5 \mathrm{~m} \Omega 180$ s exhibit a much smaller capacity loss $(6.86 \%)$ than that of the $\mathrm{LiCoO}_{2}$ electrodes $(11.31 \%)$.

The varying trend of capacities of $\mathrm{LiCoO}_{2}$ and $\mathrm{MCMB}$ electrode dismantled from BSC is similar with that of BS. The capacity loss of $\mathrm{LiCoO}_{2}$ electrode dismantled from BSC by different mode $(0.6 \mathrm{~m} 1 \mathrm{~s}, 5.0 \mathrm{~m} 30 \mathrm{~s}$ and $0.6 \mathrm{~m} 30 \mathrm{~s})$ is $0.86 \%$, $2.53 \%$ and $8.65 \%$, respectively. The capacity loss of MCMB electrode is $3.01 \%$, $3.70 \%$ and $5.19 \%$, respectively. These results show that the damage to $\mathrm{LiCoO}_{2}$ is the major factor in the capacity decrease of full battery, and the electrodes can still deliver their reversible capacity at low rate. The capacity loss of $\mathrm{LiCoO}_{2}$ electrode is related with the $\mathrm{Li}^{+} / \mathrm{Co}^{3+}$ cation mixing by the results of XRD and the capacity loss of MCMB electrode is mainly attributed to the increasing of SEI film. The water washing is an effective method to remove the SEI film $[9,27]$ and MCMB electrode dismantled from BSC by $0.6 \mathrm{~m} \Omega 30$ s is washed with water to remove the SEI film. The water washed MCMB electrode is used as the working electrode to assemble the half-cell. After being washed with water, the specific capacity of MCMB dismantled from BSC by $0.6 \mathrm{~m} \Omega 30 \mathrm{~s}$ can increase from $299.60 \mathrm{mAhg}^{-1}$ to $318.36 \mathrm{mAhg}^{-1}$ (Fig. S4), indicating that the capacity fading of anode is attributed to the SEI film. 
The reversible capacity reflects the intrinsic performance of the electrode, including structure, electric contact between active particles and conductive agent, etc. The residual capacity of $\mathrm{LiCoO}_{2}$ electrode indicates that some lithium ions can't insert into the $\mathrm{Li}_{1-\mathrm{x}} \mathrm{CoO}_{2}$ when the full battery is discharged to $3.0 \mathrm{~V}$. The residual capacity of $\mathrm{LiCoO}_{2}$ electrode may be caused by the consumption of active lithium on anode and the limit of polarization [32]. The residual capacity of $\mathrm{LiCoO}_{2}$ and $\mathrm{MCMB}$ electrode dismantled from activated battery and BS is listed in table 6. The residual capacity increases with the increase of short circuiting degree. The residual capacity of $\mathrm{LiCoO}_{2}$ electrode is higher than that of MCMB electrode, indicating that there are some lithium ions residing in the anode. According to our previous work [33], the capacity loss of short circuited battery caused by polarization is $0.27 \%, 8.46 \%$, $31.11 \%$, and $78.26 \%$, respectively, which is corresponding to different short circuiting mode $(0.6 \mathrm{~m} \Omega 1 \mathrm{~s}, 5.0 \mathrm{~m} \Omega 30 \mathrm{~s}, 0.6 \mathrm{~m} \Omega 30 \mathrm{~s}$, and $5 \mathrm{~m} \Omega 180 \mathrm{~s}$ battery). Therefore, the large polarization is an important reason for capacity fading of short circuited battery.

Table 5.

Table 6.

Normalized charged/discharged profiles of $\mathrm{LiCoO}_{2}$ and $\mathrm{MCMB}$ electrode dismantled from BS and BSC at low rate are presented in Fig. 7. The voltage profile of $\mathrm{LiCoO}_{2}$ electrode from BS by $0.6 \mathrm{~m} \Omega$ for $1 \mathrm{~s}$ has no noticeable change, whereas the polarization increases for the BS by $5.0 \mathrm{~m} \Omega 30 \mathrm{~s}, 0.6 \mathrm{~m} \Omega 30 \mathrm{~s}$, and $5.0 \mathrm{~m} \Omega 180 \mathrm{~s}$. And 
the polarization is gradually increscent as the increase of short circuiting degree. However, the polarization of battery increases after 1000 cycles and is also intensified as the rising of short circuiting degree.

The charge/discharge curves of MCMB electrode have almost no change for BS and BSC at low rate (Fig. 7b). Therefore, the polarization of full battery is mainly caused by the $\mathrm{LiCoO}_{2}$ electrode, which may be related with slow kinetics of lithium intercalation into/deintercalation from the $\mathrm{LiCoO}_{2}$ particles.

Fig. 7.

\subsection{PITT test}

PITT is a reliable technique to determine the chemical diffusion coefficient of lithium $\left(D_{\mathrm{Li}}{ }^{+}\right)$with varying voltage, in the cathode materials [34-37]. $D_{\mathrm{Li}^{+}}$can be calculated using the following equation [38]:

$$
D_{L i^{+}}=-\frac{d \ln (I)}{d t} \frac{R^{2}}{\pi^{2}}
$$

where $D_{L i}{ }^{+}$is the diffusion coefficient, $I$ is current for the electrode, $t$ is charge time, and $R$ is radii of particles.

The $D_{\mathrm{Li}}{ }^{+}$in $\mathrm{LiCoO}_{2}$ dismantled from BS and BSC is shown in Fig. 8a. For the activated cathode, it is shown that $D_{\mathrm{Li}}{ }^{+}$ranges from $\sim 10^{-12}$ to $\sim 10^{-11} \mathrm{~cm}^{2} \mathrm{~s}^{-1}$ at different electrode potentials. According to the literatures $[39,40], D_{\mathrm{Li}}{ }^{+}$in $\mathrm{LiCoO}_{2}$ varies from $\sim 10^{-13}$ to $\sim 10^{-7} \mathrm{~cm}^{2} \mathrm{~s}^{-1}$. Li diffusion in the lithium layer occurs via tetrahedral sites by 
a divacancy mechanism, and $\mathrm{Li}^{+}$migration in the solid phase is affected by the lithium concentration in $\mathrm{LiCoO}_{2}$. Therefore, $D_{L i}{ }^{+}$increases with the increase of voltage. $D_{\mathrm{Li}}{ }^{+}$ values in $\mathrm{LiCoO}_{2}$ of $\mathrm{BS}$ by $0.6 \mathrm{~m} \Omega$ for $1 \mathrm{~s}$ show almost the same behavior with that of the activated cathode. However, $D_{\mathrm{Li}}{ }^{+}$reduces with the rising of short circuiting degree, indicating that the short circuiting can increase the resistance of lithium diffusion.

$D_{\mathrm{Li}}{ }^{+}$in $\mathrm{LiCoO}_{2}$ electrode of $\mathrm{BSC}$ also reduces as the rising of short circuiting degree, which is similar with that of BS. In addition, the reduction of $D_{\mathrm{Li}}{ }^{+}$aggravates when BS is further cycled 1000 times, which suggests that the cycling can intensify the decreasing of $D_{\mathrm{Li}}{ }^{+}$in the short circuited $\mathrm{LiCoO}_{2}$ electrode. According to XRD analysis, cation mixing of $\mathrm{Li}$ and Co occurs in BSC. The diffusion ability of lithium largely depends on the interaction between lithium ion and surrounding ion $\left(\mathrm{Co}^{3+}, \mathrm{O}^{2-}\right)$ [41-43]. When Li and Co cation mixing happens, the layered structure achieves partial disorder. The vacancies appear to be randomized within the lithium layers around the Co cation because a small amount of Co cations into the lithium layer, which isn't beneficial for the migration and diffusion of lithium between lattices [44]. In addition, the cobalt ion of lithium layer rejects the lithium ion which increases the diffusion resistance of the lithium ion and reduces the diffusion coefficient.

The $D_{\mathrm{Li}}{ }^{+}$has little effect on the electrochemical performance of $\mathrm{LiCoO}_{2}$ electrode at low rate, but has remarkable effect at high rate. The rate characteristics of $\mathrm{LiCoO}_{2}$ electrodes dismantled from BS and BSC are presented in Fig. 8b. Over the entire range of rate, the cathode exhibits a similar trend. The capacity decreases gradually as the current rate increases, and the decrease extent increases with the rising of short 
circuiting degree. The capacity at $0.1 \mathrm{C}$ exhibits a little change with the increase of short circuiting, whereas the electrodes exhibit marked capacity fade with increasing current rate. These results are consistent with the $D_{\mathrm{Li}}{ }^{+}$in Fig. 8a. However, the evolutions of specific capability vs. rate are similar with that of BS. The degradation degree of BSC is intensified as the rising of short circuiting degree. The reduction of $D_{\mathrm{Li}}{ }^{+}$can lead to the increase of polarization.

Fig. 8.

\section{Conclusion}

This work presents study of the effects of short-time external short circuiting on the capacity fading during long-term cycling of $\mathrm{LiCoO}_{2} / \mathrm{MCMB}$ battery. The cycle life of the battery can be shortened by the serious short circuiting. The batteries and the retrieved electrodes are studied by SEM, XRD, EDS and electrochemical tests. External short circuiting can lead to high discharge current and high temperature. The high discharge current caused by short circuit can damage electrodes, leaving vacancies in structure, and the damage of electrode can lead to the reduction of $D_{\mathrm{Li}}{ }^{+}$. The high temperature can result in the increase of SEI film. The charged/discharged cycling can intensify the damage of $\mathrm{LiCoO}_{2}$ structure, the increase of SEI film, and further leading to the increase of polarization. The polarization and the capacity loss of electrodes are the main reason of capacity fading for short circuited battery during long-term cycling and the polarization is mainly caused by $\mathrm{LiCoO}_{2}$ electrode. 


\section{Acknowledgments}

This work was supported by the National High Technology Research and

Development Program (863 Program) of China (No. 2012AA110203), the National Science Foundation of China (No. 51202047), the Heilongjiang Postdoctoral Fund

(No. LBH-Z11141), and the Fundamental Research Funds for the Central Universities

(No. HIT. NSRIF. 2011022). We would like to thank Professor Galen Leonhardy for English modification.

\section{Reference}

[1] J.M. Tarascon, M. Armand, Nature 414 (2001) 359-367.

[2] B. Dunn, H. Kamath, J.M. Tarascon, Science 334 (2011) 928-935.

[3] Y.Z. Cui, C.Y. Du, G.P. Yin, Y.Z. Gao, L.L. Zhang, T. Guan, L.J. Yang, F.P. Wang, J. Power Sources 279 (2015) 123-132.

[4] S. Tobishma, K. Takei, Y. Sakurai, J. Yamaki, J. Power Sources 90(2000) $188-195$.

[5] J. Cho, Electrochim. Acta 48 (2003) 2807-2811.

[6] C.K. Lin, Y. Ren, K. Amine, Y. Qin, Z.H. Chen, J. Power Sources 230 (2013) $32-37$.

[7] S.I. Tobishima, J.I. Yamaki, J. Power Sources 81-82 (1999) 882-886.

[8] R. Spotnitz, J. Franklin, J. Power Sources 113 (2003) 81-100.

[9] L.L. Zhang, Y.L. Ma, X.Q. Cheng, C.Y. Du, T. Guan, Y.Z. Cui, S. Sun, P.J. Zuo, Y.Z. Gao, G.P. Yin. J. Power Sources 293 (2015) 1006-1015.

[10]K. Smith, C.Y. Wang, J. Power Sources 160 (2006) 662-673. 
[11]R.A. Leising, M.J. Palazzo, E.S. Takeuchi, K.J. Takeuchi, J. Electrochem. Soc. 148 (2001) A838-A844.

[12]F. Larsson, B.E. Mellander, J. Electrochem. Soc.161 (2014) A1611-A1617.

[13]J.A. Choi, S.H. Kim, D.W. Kim, J. Power Sources 195 (2010) 6192-6196.

[14] S.S. Zhang, J. Power Sources 164 (2007) 351-364.

[15]H. Maleki, J.N. Howard, J. Power Sources 191 (2009) 568-574.

[16]L.J. Yang, X.Q. Cheng, Y.L. Ma, S.F. Lou, Y.Z. Cui, T. Guan, G.P. Yin, J. Electrochem. Soc.160 (2013) A2093-A2099.

[17]C. Chen, J. Lui, K. Armine, J. Power Sources 96 (2001) 321-328.

[18]H. Kitaura, A. Hayashi, K. Tadanaga, M. Tutsumisago, J. Electrochem. Soc. 156 (2009) A114-A119.

[19]N. Schweikert, A. Hofmann, M. Schulz, M. Scheuermann, S. T. Boles, T. Hanemann, H. Hahn, S. Indris, Journal of Power Sources 228 (2013) 237-243.

[20]Y. Zheng, Y.B. He, K. Qian, B.H. Li, X.D. Wang, J.L. Lia, S.W. Chiang, C. Miao, F.Y. Kang, J.B. Zhang, Electrochim. Acta 176 (2015) 270-279.

[21]K. Jalkanen, J. Karppinen, L. Skogström, T. Laurila, M. Nisula, K. Vuorilehto, Appl. Energy 154 (2015) 160-172.

[22]L. Bodenes, R. Naturel, H. Martinez, R. Dedryvère, M. Menetrier, L. Croguennec, J.P. Pérès, C. Tessier, F. Fischer, J. Power Sources 236 (2013) 265-275

[23]P. Maire, H. Kaiser, W. Scheifele, P. Novák, J. Electroanal. Chem. 644 (2010) $127-131$.

[24]D. Aurbach, E. Zinigrad, Y. Cohen, H. Teller, Solid State Ion. 148 (2002) 
$405-416$.

[25]C.C. Chang, T.K. Chen, J. Power Sources 193 (2009) 834-840.

[26] A. Ueda, T.Ohzuku, J. Electrochem. Soc. 141 (1994) 2010-2014.

[27]L.J. Yang, X.Q. Cheng, Y.Z. Gao, P.J. Zuo, Y.L. Ma, C.Y. Du, B. Shen, Y.Z. Cui, T. Guan, G.P. Yin, Appl. Mater. Interfaces 6 (2014) 12962-12970.

[28]H. Gabrisch, R. Yazami, B. Fultz, J. Electrochem. Soc. 151 (2004) A891-A897.

[29]K. Maher, R. Yazami, Electrochim. Acta 101 (2013) 71-78.

[30]D. Wong, B. Shrestha, D.A. Wetz , J. M. Heinzel, J. Power Sources 280 (2015) $363-372$.

[31]Y. Ozawa, R. Yazami, B. Fultz, J. Power Sources 119-121 (2003) 918-923.

[32]J. Vetter, P. Novák, M.R. Wagner, C. Veit, K.C. Möller, J.O. Besenhard, M. Winter, M. Wohlfahrt-Mehrens, C. Vogler, A. Hammouche, J. Power Sources 147 (2005) 269-281.

[33]T. Guan, P.J. Zuo, S. Sun, C.Y. Du, L.L. Zhang, Y.Z. Cui, L.J. Yang, Y.Z. Gao, G.P. Yin, F.P. Wang, J. Power Sources 268 (2014) 816-823.

[34]Y.H. Rho, K.S. Kanamura, J. Electrochem. Soc. 151 (2004) A1406-A1411.

[35]S. Patoux, C. Masquelier, Chem. Mater. 14 (2002) 2334-2341.

[36]J. Xie, N. Imanishi, T. Zhang, A. Hirano, Y. Takeda, O. Yamamoto, Electrochim. Acta 54 (2009) 4631-4637.

[37]C. Delacourt, M. Ati, J.M. Tarascon, J. Electrochem. Soc. 158 (2011) A741-A749.

[38]J.C. Li, F.Q Yang, X.C. Xiao, M. W. Verbrugge, Y.T. Cheng, Electrochim. Acta 75 
(2012) 56-61.

[39]J.M. McGraw, C.S. Bahn, P.A. Parilla, J.D. Perkins, D.W. Readey, D.S. Ginley, Electrochim. Acta, 45 (1999) 187-196.

[40] Y.I. Jang, B.J. Neudecker, N.J. Dudney, Electrochem. Solid-State Lett., 4(2001) A74-A77.

[41]R Darling, J Newman, J. Electrochem. Soc., 146 (1999) 3765-3772.

[42]B.C. Han, A. Van der Ven, D. Morgan, G. Ceder, Electrochim. Acta, 49 (2004) $4691-4699$.

[43]J. Bisquert, V.S. Vikherenko, Electrochim. Acta, 47 (2002) 3977-3988.

[44]J.P. Diard, C. Montella, J. Electroanal. Chem., 557 (2003) 19-36. 

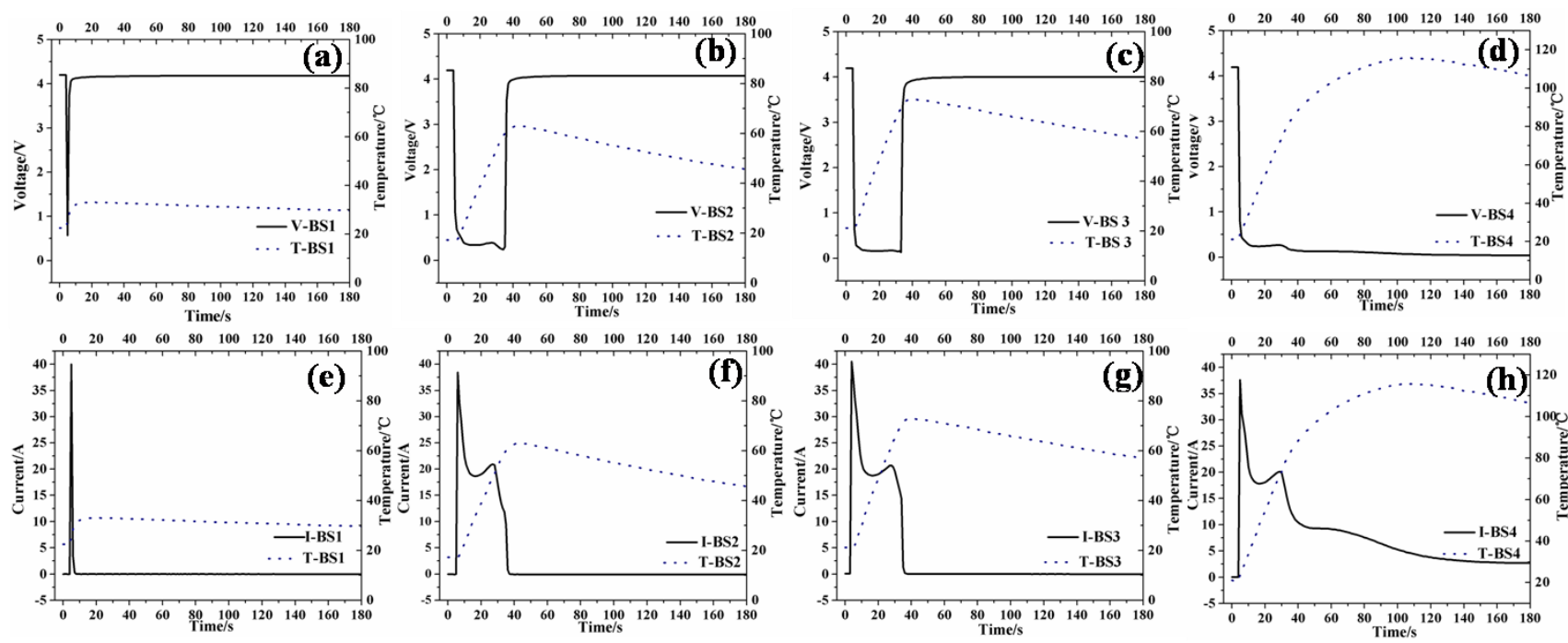

Fig. 1 

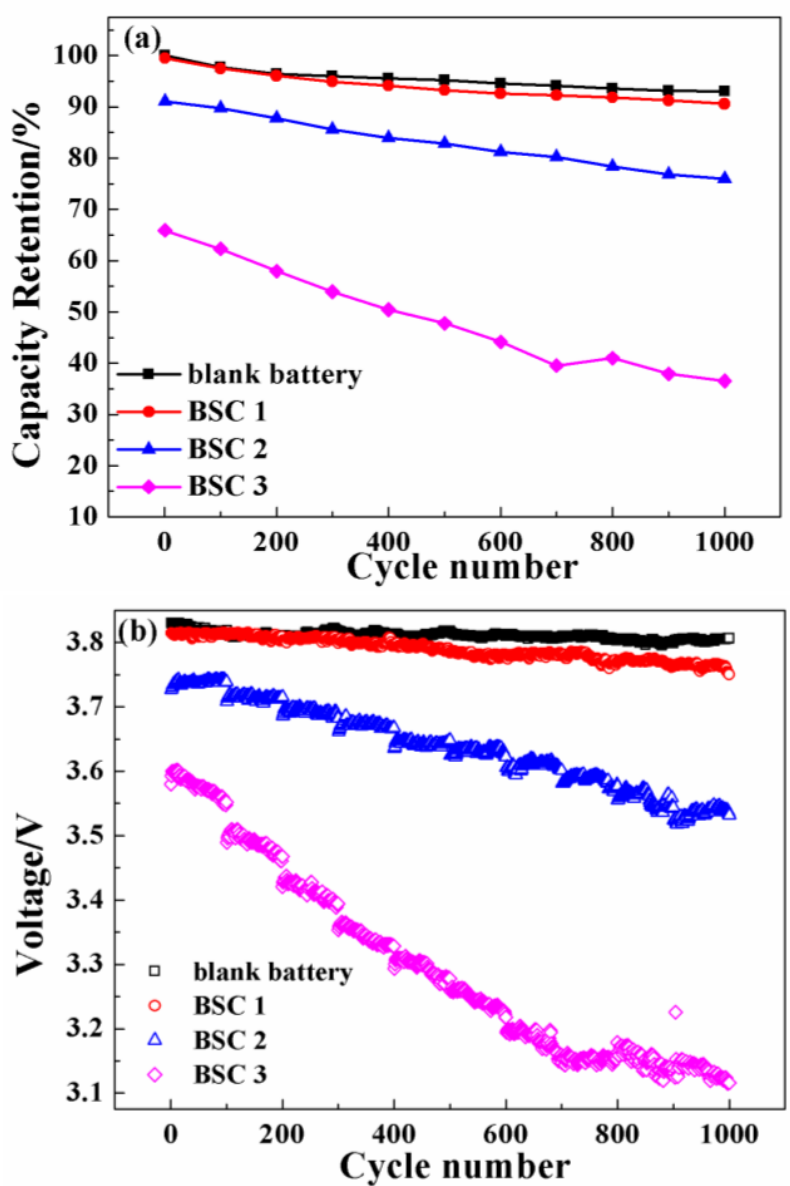

Fig. 2 


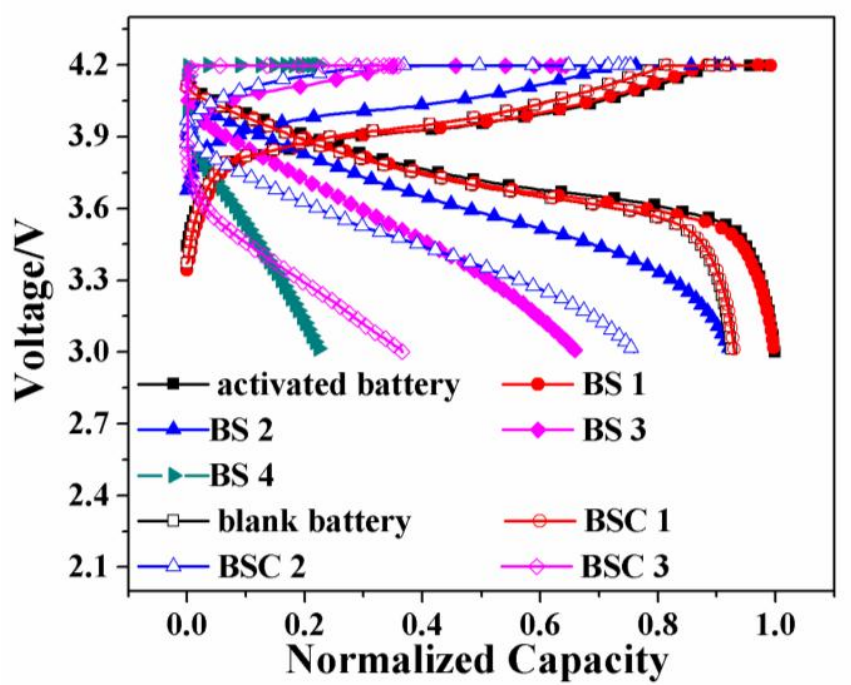

Fig. 3 

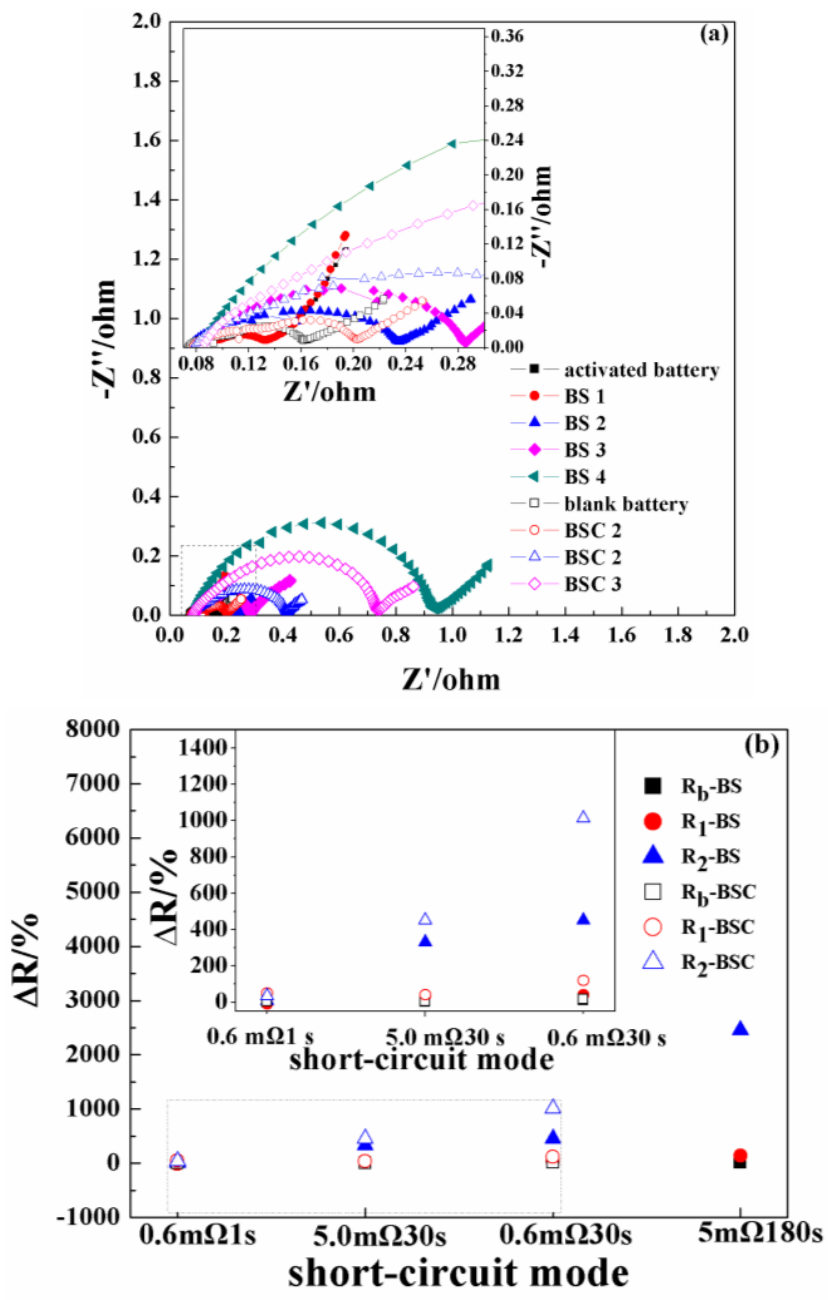

Fig. 4 

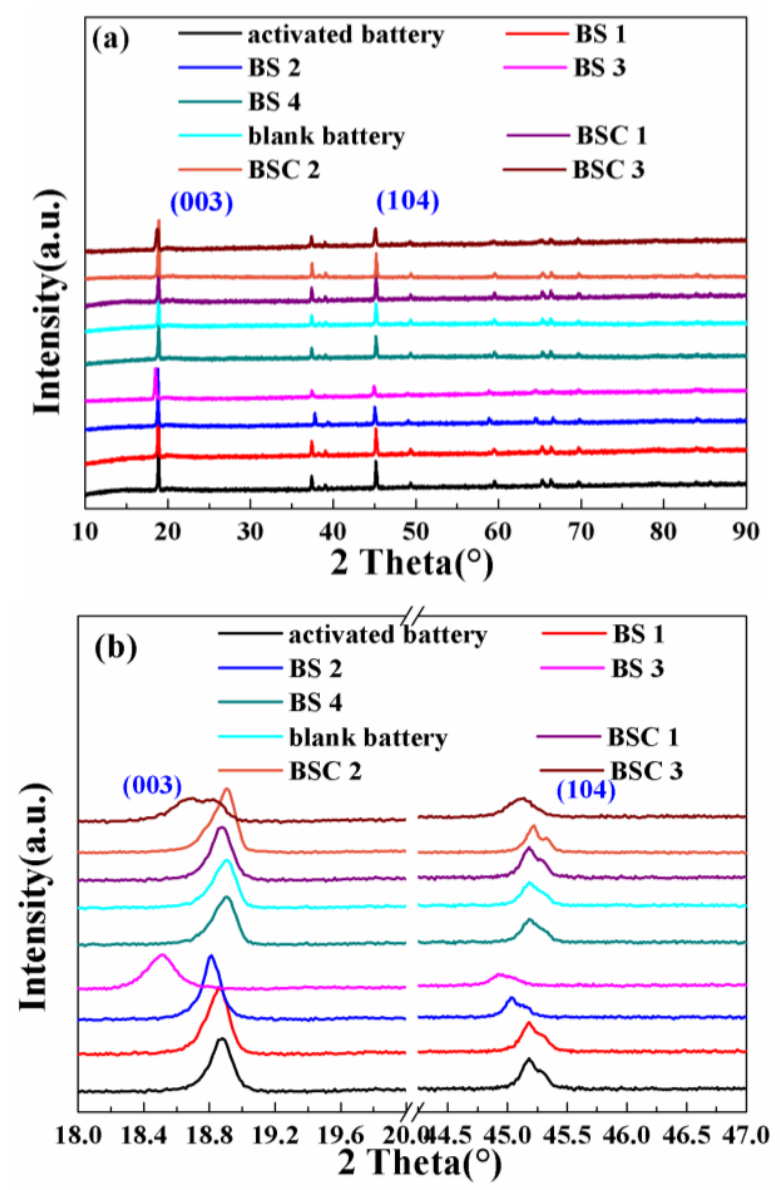

Fig. 5 

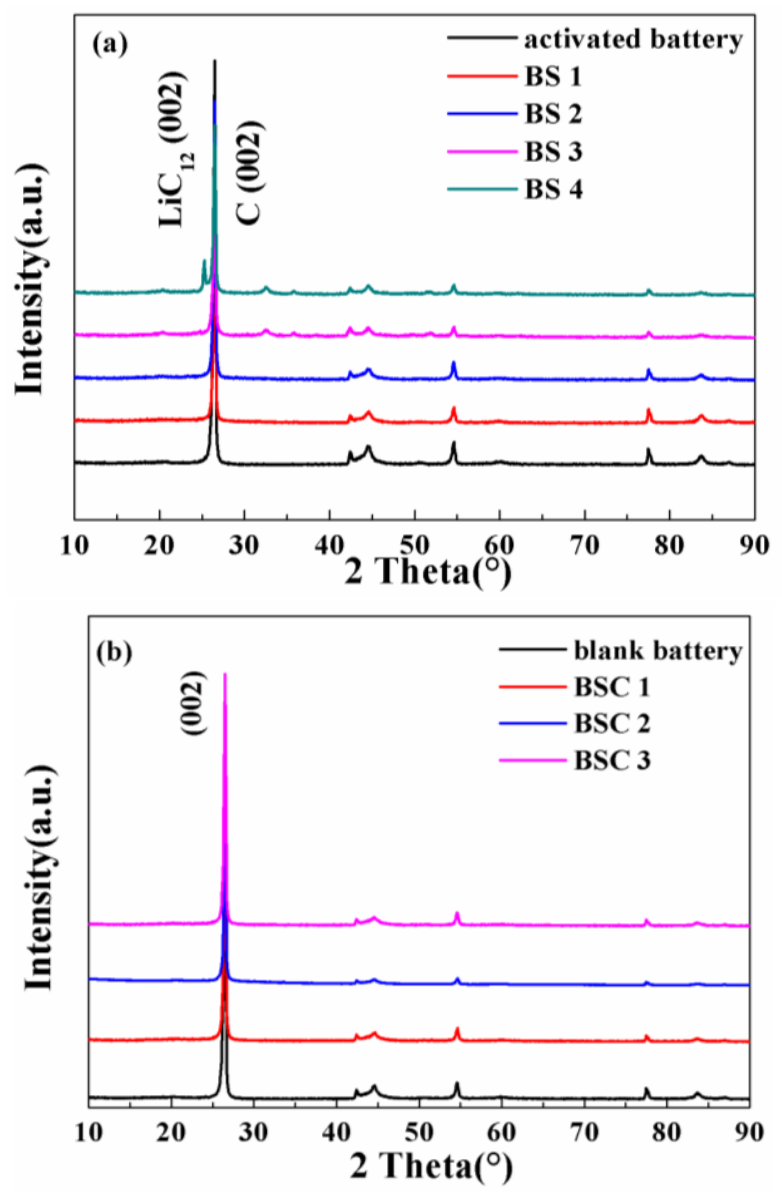

Fig. 6 

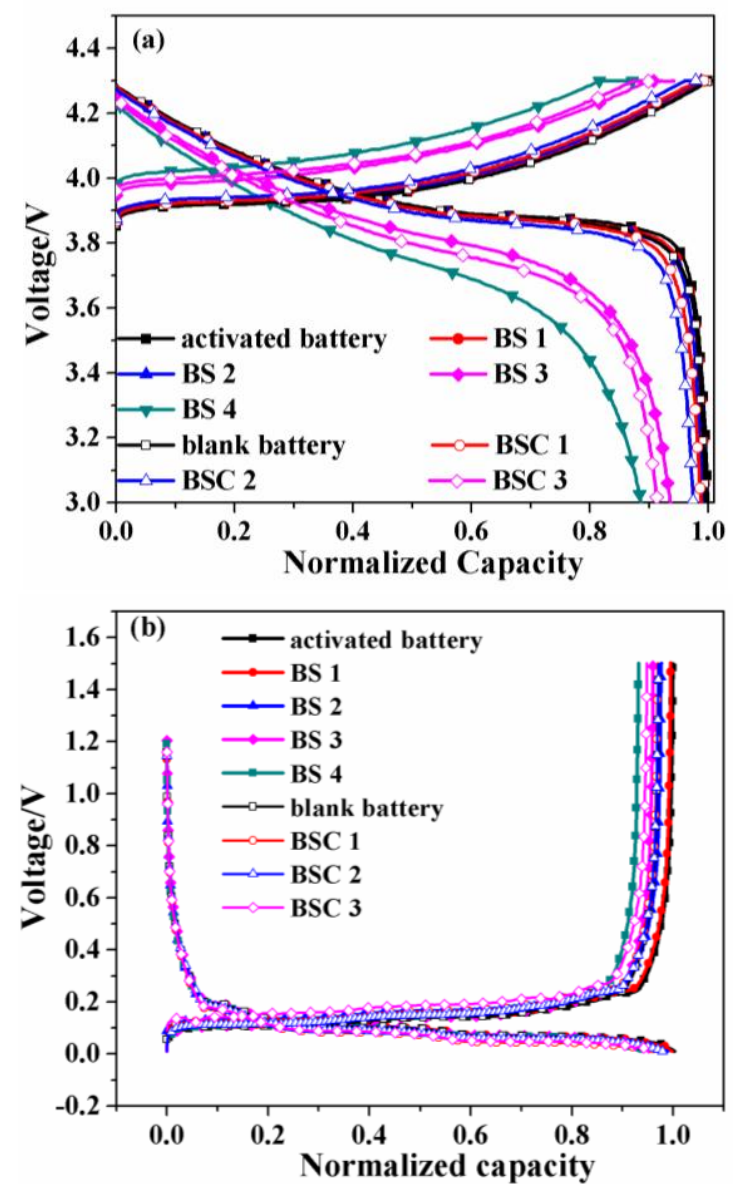

Fig. 7 


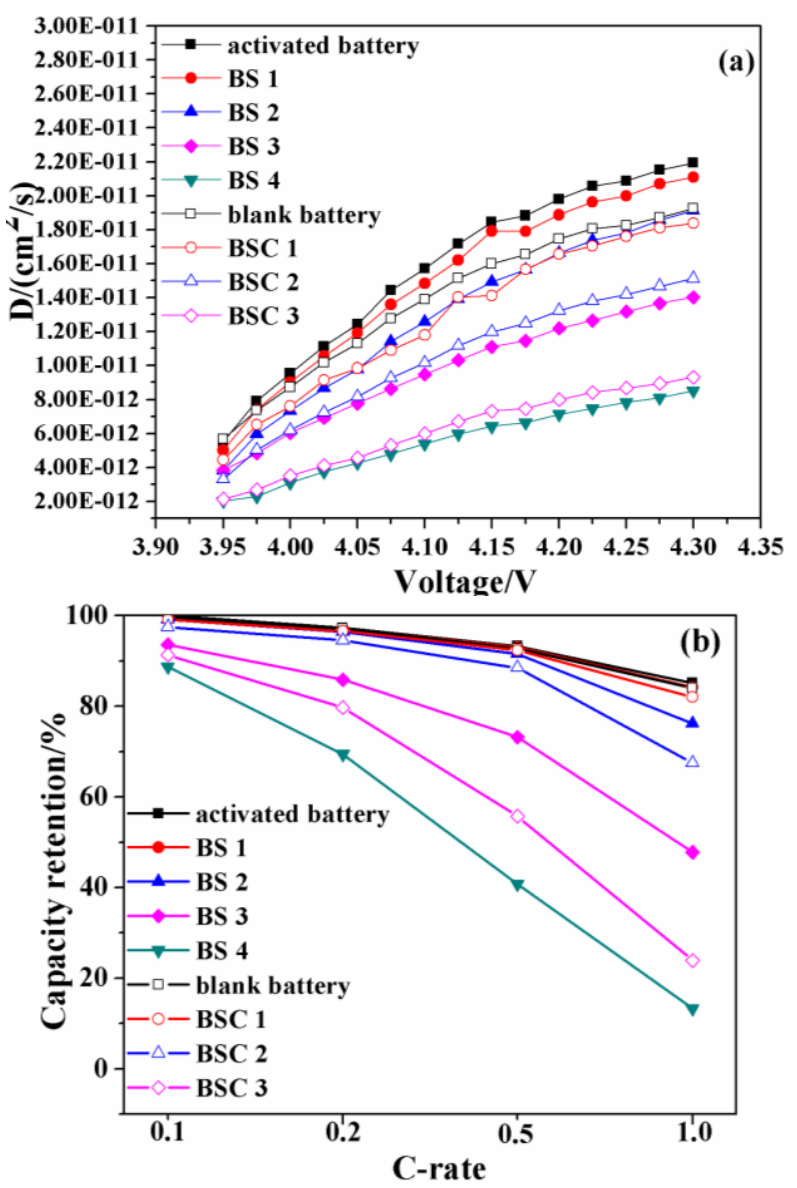

Fig. 8 


\section{List of table captions}

Table 1 . The external short circuiting mode of battery and the abbreviation.

Table 2. The $\mathrm{Q}_{1}, \mathrm{Q}_{1000}$ and $\mathrm{R}$ of batteries.

Table 3. EDS results on the surface of the MCMB electrodes dismantled from BS.

Table 4. The evolution of the intensity ratio of $\mathrm{I}_{003} / \mathrm{I}_{104}$ peaks intensity ratio and the (003) peak FWHM with short circuiting degree.

Table 5. Ratios of capacity loss of $\mathrm{LiCoO}_{2}$ electrode and MCMB electrode dismantled from BS and BSC.

Table 6. The residual capacities of the $\mathrm{LiCoO}_{2}$ and $\mathrm{MCMB}$ electrode materials dismantled from BS. 
Table 1

\begin{tabular}{ccccccccc}
\hline & \multicolumn{4}{c}{ BS } & \multicolumn{5}{c}{ BSC } \\
\hline Short circuiting & $0.6 \mathrm{~m} \Omega$ & $5.0 \mathrm{~m} \Omega$ & $0.6 \mathrm{~m} \Omega$ & $5.0 \mathrm{~m} \Omega$ & $0.6 \mathrm{~m} \Omega$ & $5.0 \mathrm{~m} \Omega$ & $0.6 \mathrm{~m} \Omega$ \\
mode & $1 \mathrm{~s}$ & $30 \mathrm{~s}$ & $30 \mathrm{~s}$ & $180 \mathrm{~s}$ & $1 \mathrm{~s}$ & $30 \mathrm{~s}$ & $30 \mathrm{~s}$ \\
symbol & BS1 & BS2 & BS3 & BS4 & BSC1 & BSC2 & BSC3 \\
\hline
\end{tabular}


Table 2

\begin{tabular}{cccc}
\hline short circuiting mode & $\mathrm{Q}_{1000} / \%$ & $\mathrm{Q}_{1} / \%$ & $\mathrm{R} / \%$ \\
\hline without short circuiting & 6.94 & - & - \\
$0.6 \mathrm{~m} \Omega 1 \mathrm{~s}$ & 9.43 & 0.53 & 5.62 \\
$5.0 \mathrm{~m} \Omega 30 \mathrm{~s}$ & 24.10 & 8.92 & 37.01 \\
$0.6 \mathrm{~m} \Omega 30 \mathrm{~s}$ & 63.46 & 34.96 & 55.08 \\
\hline
\end{tabular}


Table 3

\begin{tabular}{cccccc}
\hline & \multicolumn{5}{c}{ Atomic/\% } \\
\cline { 2 - 6 } Element & activated & BS 1 & BS 2 & BS 3 & BS 4 \\
& battery & & 89.70 & 87.37 & 60.64 \\
\hline Carbon & 92.96 & 93.06 & 6.78 & 9.02 & 34.50 \\
Oxygen & 3.90 & 3.69 & 3.52 & 3.61 & 4.86 \\
Fluorine & 3.14 & 3.25 & & & \\
\hline
\end{tabular}


Table 4

\begin{tabular}{ccccc}
\hline & \multicolumn{2}{c}{$\mathrm{I}_{003 / 104}$} & \multicolumn{2}{c}{ FWHM } \\
\cline { 2 - 5 } & BS & BSC & BS & BSC \\
\hline without short circuiting & 2.033 & 1.669 & 0.114 & 0.156 \\
$0.6 \mathrm{~m} \Omega$ 1s & 2.166 & 1.468 & 0.122 & 0.143 \\
$5.0 \mathrm{~m} \Omega$ 30s & 1.815 & 1.280 & 0.138 & 0.160 \\
$0.6 \mathrm{~m} \Omega 30 \mathrm{~s}$ & 1.758 & 1.088 & 0.142 & 0.538 \\
\hline
\end{tabular}


Table 5.

\begin{tabular}{ccc}
\hline & Capacity loss of $\mathrm{LiCoO}_{2}$ & Capacity loss of MCMB \\
& electrode/\% & electrode/\% \\
\hline BS 1 & 0.00 & 0.00 \\
BS 2 & 0.47 & 0.47 \\
BS 3 & 0.93 & 1.23 \\
BS 4 & 6.39 & 4.52 \\
blank battery & 11.31 & 6.86 \\
BSC 1 & 0.40 & 2.88 \\
BSC 2 & 0.86 & 3.01 \\
BSC 3 & 2.53 & 3.70 \\
\hline
\end{tabular}


Table 6.

\begin{tabular}{ccc}
\hline & $\begin{array}{c}\text { residual of } \mathrm{LiCoO}_{2} \\
\text { electrode/mAh }\end{array}$ & $\begin{array}{c}\text { residual of } \mathrm{MCMB} \\
\text { electrode/mAh }\end{array}$ \\
\hline activated battery & 0.36 & 0.03 \\
BS 1 & 0.42 & 0.04 \\
BS 2 & 0.63 & 0.34 \\
BS 3 & 1.37 & 1.14 \\
BS 4 & 3.11 & 2.96 \\
\hline
\end{tabular}

